\title{
Luiz Roberto Vialle (Ed.): AOSpine Masters Series, Volume 6: Thoracolumbar Spine Trauma Edition, Guest-edited by Carlo Bellabarba, Frank Kandziora
}

\section{Thieme Verlag, New York, Stuttgart, Delhi, Rio, 2015, 236 pp, Hardcover, EUR (D) 109.99, EUR (A) 113.10, CHF 126,00, ISBN: 978-1-62623-225-9}

\section{Pr Pierre Kehr ${ }^{1}$}

Received: 20 April 2016/Accepted: 25 April 2016/Published online: 13 May 2016

(C) Springer-Verlag France 2016

This sixth volume of the series AOSpine Master degrees Series, dedicated to the traumas of the thoraco-lumbar spine, is a collective work written by great names of the surgery of the spine, orthopedists and neurosurgeons.

After a recall of classification AO of these fractures, a long chapter details the radiological evaluation.

The mini-invasive accesses of the thoraco-lumbar fractures by posterior access and then by former access are the object of two large chapters. The fractures of the cervicothoracic junction are added, as well as the accesses traspédiculaires and by costo-transversectomy.

The burst fractures and their treatment, the differences between thoraco-lumbar and lumbar fractures, the fractures on covered over with soil $\mathrm{N}$ osteoporotic, on spondylarthrite ankylosante and finally fixings on the basin are the object of special chapters.

Thus, work is very complete, with advising with all the orthopedists and neurosurgeons confronted with the traumatology of the thoraco-lumbar spine, which they are seniors or initial.

Compliance with ethical standards

Conflict of interest None.

Pr Pierre Kehr

pierre.kehr@gmail.com

1 Strasbourg, France 